\title{
High grade anorectal stricture complicating Crohn's disease: endoscopic treatment using insulated-tip knife
}

\author{
Hyung Ku Chon, Ik Sang Shin, Sang Wook Kim, Soo Teik Lee \\ Division of Gastroenterology, Department of Internal Medicine, Chonbuk National University College of Medicine and Hospital, Jeonju, Korea
}

Endoscopic treatments have emerged as an alternative to surgery, in the treatment of benign colorectal stricture. Unlike endoscopic balloon dilatation, there is limited data on endoscopic electrocautery incision therapy for benign colorectal stricture, especially with regards to safety and long-term patency. We present a case of a 29-year-old female with Crohn's disease who had difficulty in defecation and passing thin stools. A pelvic magnetic resonance imaging scan, gastrograffin enema, and sigmoidoscopy showed a high-grade anorectal stricture. An endoscopic insulated-tip knife incision was successfully performed to resolve the problem. From our experience, we suggest that endoscopic insulated-tip knife treatment may be a feasible and effective modality for patients with short-segment, very rigid, fibrotic anorectal stricture. (Intest Res 2016;14:285-288)

Key Words: Crohn diseases; Anorectal stricture; Endoscopic insulated-tip knife

\section{INTRODUCTION}

Stricture as a complication of CD is a significant clinical problem. It is reported by some studies to function as a predictor of poor clinical outcome. ${ }^{1}$ There are no specific anti-fibrotic therapies. ${ }^{2}$ In the past, surgical treatments such as bowel resection or strictureplasty were the preferred treatment approach for strictures associated with CD, but the other forms of conservative treatment have gained favor since recurrent, chronic nonhealing wounds and incontinence are the adverse events occurring after operation. ${ }^{3}$ Today, a variety of endoscopic approaches for the treatment of strictures are being used. We described a case of CD in a 29-year-old female patient with anorectal stricture, successfully treated with endoscopic therapy. To the best of our knowledge, this is the first reported case of an anorectal stricture in CD where an endoscopic insulated tip knife was used for treatment.

\section{CASE REPORT}

A 29-year-old female, diagnosed with CD in 2002, presented with pain in her lower abdomen for the previous 7 days. Twelve months before this episode, she complained of difficulty in defecation and of passing "ribbon like" stools. Recently, her stricture symptoms were getting worse. When she was first diagnosed, the CD status of the patient, according to the Montreal classification, was ileocolon (L3), without perianal involvement and of a nonstricturing nonpenetrating (B1) type. She had been treated with adalimumab $40 \mathrm{mg} / 0.8$ $\mathrm{ml}$ solution subcutaneously, every other week, since 2005 . Laboratory data was unremarkable. A pelvic MRI scan (Fig. 1A, B) and gastrograffin enema (Fig. 2) were performed and these investigations revealed an anorectal stricture about $1.4 \mathrm{~cm}$ in size. After informed consent had been obtained, a flexible sigmoidoscopy was performed and revealed, with the exception of two tiny openings, a tight, fibrotic, benignlooking anorectal stricture. It was situated $5 \mathrm{~cm}$ from the

Received August 11, 2015. Revised October 19, 2015. Accepted November 3, 2015.

Correspondence to Soo Teik Lee, Division of Gastroenterology, Department of Internal Medicine, Chonbuk National University Medical School and Hospital, 20

Geonji-ro, Deokjin-gu, Jeonju 54907, Chonbuk, Korea. Tel: +82-63-250-1533, Fax: +82-63-254-1609, E-mail: soo@cuh.co.kr

Financial support: None. Conflict of interest: None.

๑ Copyright 2016. Korean Association for the Study of Intestinal Diseases. All rights reserved.

This is an Open Access article distributed under the terms of the Creative Commons Attribution Non-Commercial License (http://creativecommons.org/licenses/by-nc/4.0)

which permits unrestricted non-commercial use, distribution, and reproduction in any medium, provided the original work is properly cited. 

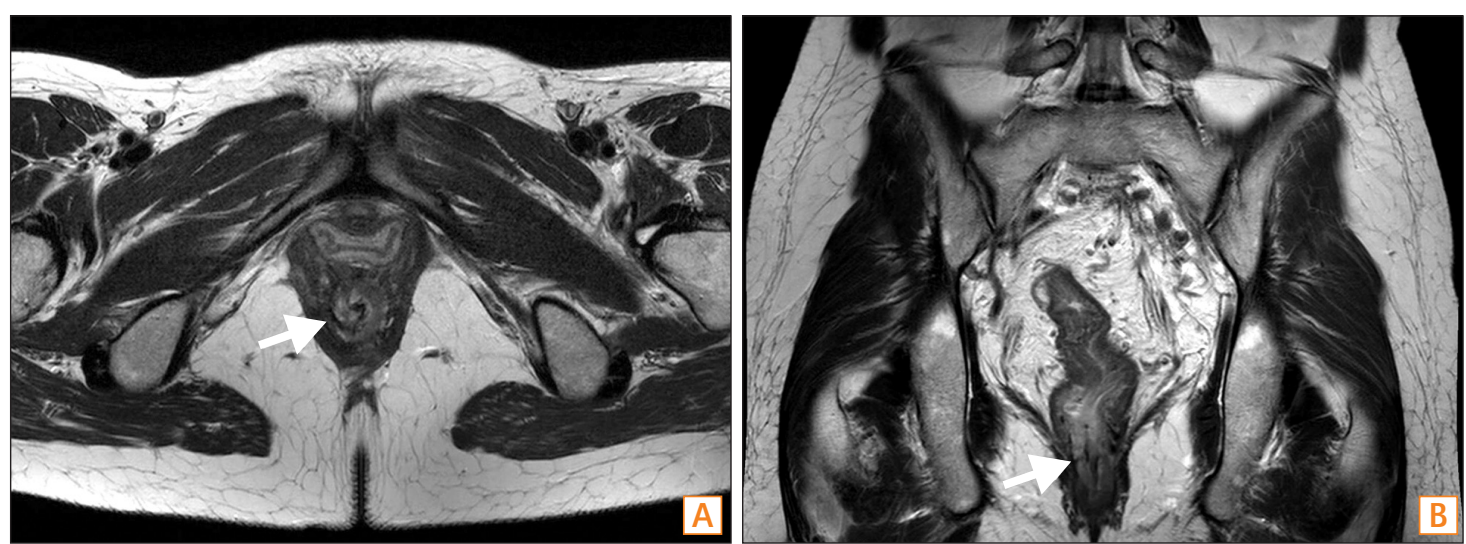

Fig. 1. Pelvic MRI finding. Axial (A) and coronal (B) T2-weighted MR image demonstrated circumferential and short segment stricture of anorectal area (arrow in $\mathrm{A}$ and $\mathrm{B}$ ).

anal verge and prevented the passage for the scope into the anal canal. The sizes of the two holes were approximately 1 $\mathrm{mm}$ and $5 \mathrm{~mm}$ (Fig. 3A). The fibrotic tissue near the 1-mm hole was removed via hot biopsy and was widened to about $1 \mathrm{~cm}$ (Fig. 3B, C). The tissue causing the stricture between the $1 \mathrm{~cm}$ and $5 \mathrm{~mm}$ holes was incised and cut horizontally with the insulated-tip knife, which widened the stricture area (Fig. 3D, E). After the procedure, the patient did not experience bleeding, perforation or any other complications. Two days later, colonoscopy demonstrated pseudo-polyps of the ileocecal valve and the development of regenerative tissue at the stricturotomy site of the anorectum. Anorectal manometry revealed normal anal sphincter tone and sensation of stooling in the rectum, as well as normal movement of the rectal and anal muscles. A follow-up sigmoidoscopy was performed 1 year later (Fig. 3F). Although there was slight luminal narrowing, there was no relapse of the anorectal strictures and the stool caliber was normal. The patient is currently being monitored as an outpatient.

\section{DISCUSSION}

Although anorectal stricture in CD may be more common, however, is asymptomatic in many cases. Keighley and Al$\operatorname{lan}^{4}$ showed that the prevalence of anorectal stricture was about $8.9 \%$ among patients with CD enrolled in their study. The most well-known treatment modality for stricturing CD includes endoscopic balloon dilatation or bougie combined with local steroid injection. ${ }^{2,5}$ The long-term success rate of endoscopic balloon dilatation is high (80\%). ${ }^{6}$ However, several cases published ineffectiveness of the balloon dilatation, especially in very tight fibrotic strictures that can be caused by recurrent inflammatory acutisations over a long period of

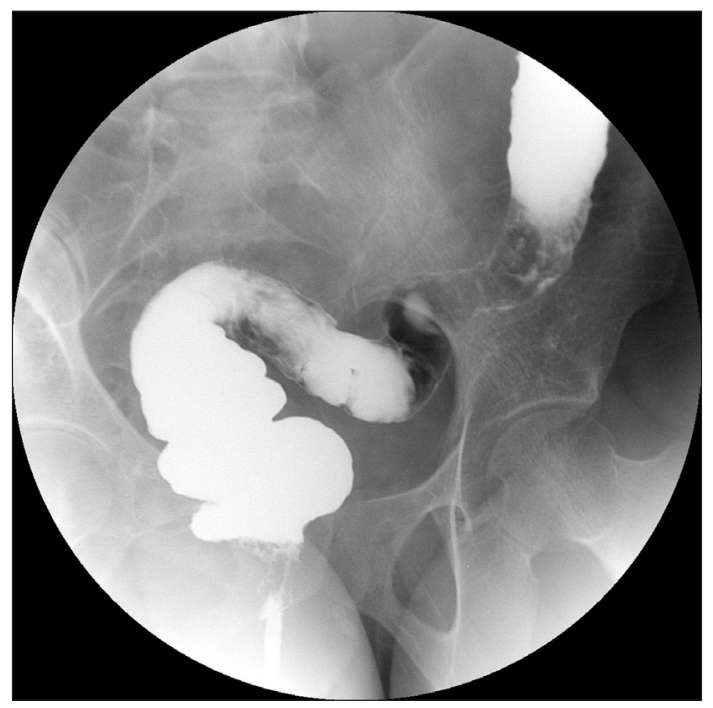

Fig. 2. Gastrograffin enema finding. It showed high-grade anorectal stricture, a segment about $1.4 \mathrm{~cm}$ in size.

time, as was the case with our patient. In these case reports, endoscopic needle-knife treatment ${ }^{7}$ or digital dilation with topical application of mitomycin $\mathrm{C}$ at stricture site were used as an alternative therapy.

Endoscopic needle knife electro-incision for stricture had been applied to area of refractory Schatzki's ring, ${ }^{8}$ refractory esophago-gastric anastomosis stricture, ${ }^{9}$ refractory colonic anastomotic strictures, ${ }^{10,11}$ treatment of congenital pyloric stenosis, ${ }^{12}$ and benign colorectal stricture in $\mathrm{CD} .{ }^{6}$ Nonetheless, we used an endoscopic insulated-tip knife instead of needle knife for high-grade fibrotic anorectal stricture. This tip of the insulated knife consists of a ceramic ball, which permits cutting only at the side of the knife. This device allows more control during intervention and prevents inad- 

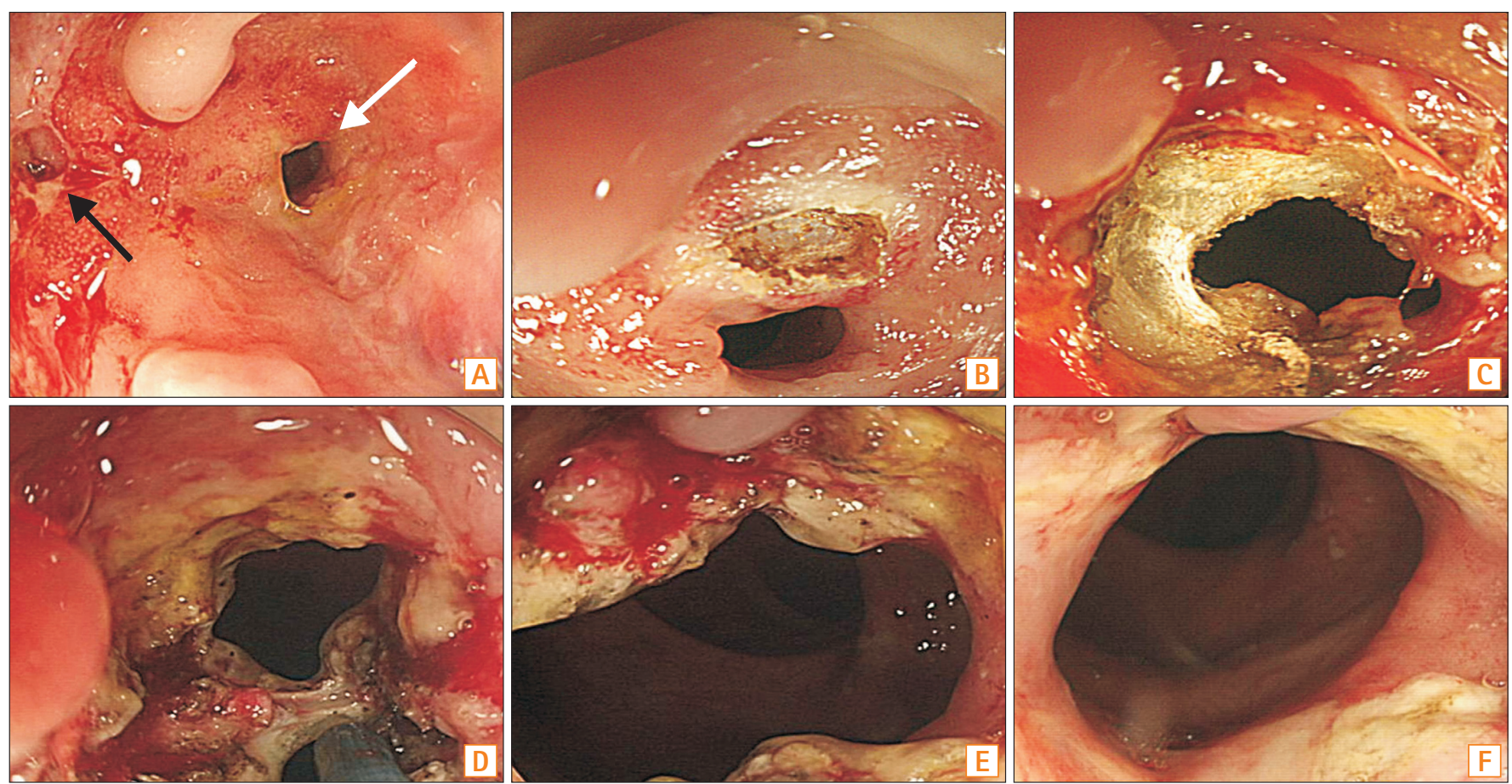

Fig. 3. Endoscopic findings of anorectal stricture (A) Initial sigmoidoscopy, showing a luminal stricture with fibrotic tissue and exudate except for two tiny holes (1-mm [black arrow] and 5-mm [white arrow]) $(B, C)$ The fibrotic tissue near the $1 \mathrm{~mm}$ hole was removed via hot biopsy and widened to about $1 \mathrm{~cm}$. (D) Endoscopic electrocautery incision using an insulated-tip knife through the widened hole was carried out between the 1-cm and 5-mm hole (E) Stricture area was widened (F) Follow-up sigmoidoscopy after 1 year.

vertent contact of the tip of the conducting cautery, thus potentially minimizing the risk of perforation when compared to needle knife used during electrocautery therapy. ${ }^{13}$

There are occasional reports of successful treatment of the esophagus $^{14}$ and duodenal stenosis, ${ }^{15}$ as well as the postoperative bowel and airway obstruction using the insulated-tip knife. ${ }^{16}$ However, there have been no previous reports of the successful treatment in patients with CD-associated stricture via an endoscopic insulated-tip knife. This could be because this procedure requires a specific expertise. Although the need for prospective collection of data and more experience remains, we suggest that endoscopic insulated-tip knife treatment might provide an alternative treatment to balloon dilatation and endoscopic needle knife incision, for patients with short-segment, very rigid, fibrotic anorectal stricture.

\section{REFERENCES}

1. Brochard C, Siproudhis L, Wallenhorst T, et al. Anorectal stricture in 102 patients with Crohn's disease: natural history in the era of biologics. Aliment Pharmacol Ther 2014;40:796-803.
2. Rieder F, Zimmermann EM, Remzi FH, Sandborn WJ. Crohn's disease complicated by strictures: a systematic review. Gut 2013;62:1072-1084.

3. Krieger BR, Steinhagen RM. Perianal Crohn's disease - A surgical perspective. Semin Colon Rectal Surg 2012;23:125-129.

4. Keighley MR, Allan RN. Current status and influence of operation on perianal Crohn's disease. Int J Colorectal Dis 1986;1:104107.

5. Brooker JC, Beckett CG, Saunders BP, Benson MJ. Long-acting steroid injection after endoscopic dilation of anastomotic Crohn's strictures may improve the outcome: a retrospective case series. Endoscopy 2003;35:333-337.

6. Thienpont C, D'Hoore A, Vermeire S, et al. Long-term outcome of endoscopic dilatation in patients with Crohn's disease is not affected by disease activity or medical therapy. Gut 2010;59:320-324.

7. Kerkhof M, Dewint P, Koch AD, van der Woude CJ. Endoscopic needle-knife treatment of refractory ileo-ascending anastomotic stricture. Endoscopy 2013;45(Suppl 2):E57-E58.

8. DiSario JA, Pedersen PJ, Bichiş-Canoutas C, Alder SC, Fang JC. Incision of recurrent distal esophageal (Schatzki) ring after dilation. Gastrointest Endosc 2002;56:244-248. 
9. Brandimarte G, Tursi A. Endoscopic treatment of benign anastomotic esophageal stenosis with electrocautery. Endoscopy 2002;34:399-401.

10. Brandimarte G, Tursi A, Gasbarrini G. Endoscopic treatment of benign anastomotic colorectal stenosis with electrocautery. Endoscopy 2000;32:461-463.

11. Hagiwara A, Togawa T, Yamasaki J, Shirasu M, Sakakura C, Yamagishi H. Endoscopic incision and balloon dilatation for cicatricial anastomotic strictures. Hepatogastroenterology 1999;46:997-999.

12. Ibarguen-Secchia E. Endoscopic pyloromyotomy for congenital pyloric stenosis. Gastrointest Endosc 2005;61:598-600.
13. Baron TH. Snares, knives, and scissors. Tech Gastrointest Endosc 2006;8:22-27.

14. Hyun JJ, Chun HJ, Keum B, et al. Weblike stenosis due to gastroesophageal reflux disease, treated with an insulation-tipped diathermic knife-2 (IT-2). Endoscopy 2010;42(Suppl 2):E110.

15. Lee SS, Hwang ST, Jang NG, et al. A case of congenital duodenal web causing duodenal stenosis in a down syndrome child: endoscopic resection with an insulated-tip knife. Gut Liver 2011;5:105-109.

16. Koh KH, Kim SJ, Park S, et al. Two cases of central airway obstruction treated with an insulation-tipped diathermic knife-2. Korean J Med 2014;86:755-760. 